\title{
Boosting Indonesia's Tourism Sector to be Competitive
}

Oleh: Arella Kartikaputri

Email: $\underline{\text { arellaptr@gmail.com }}$

Indonesia has many attractive tourist destinations, such as Borobudur Temple, Mount Bromo, Lake Toba, Raja Ampat, Labuan Bajo, and others. Indonesia's tourism sector continues to be encouraged to become one of the major foreign exchange earner sectors and has a direct impact on the people involved in tourism activities in the hope of covering current account deficits, increasing employment, and moving Micro, Small and Medium Enterprises (MSMEs). It should be understood that the tourism sector has direct and indirect impacts on the domestic economy. The development of the tourism sector is able to absorb labor so that it has an impact on increasing economic growth and can directly increase capital flows to Indonesia.

The government of Indonesia tries to increase the number of overseas visitors through the exemption of visitor visas for 169 countries, accelerate the development of transportation infrastructure so that tourist destinations are accessible, and echo the image of Indonesian tourism Wonderful Indonesia. However, the target number of visitors tends to be difficult to achieve due to various factors, such as volcanic eruptions, tsunami disasters, and others.

The contribution of tourism to the Gross Domestic Product (GDP) and foreign exchange supply for Indonesia is still lagging behind Singapore, Thailand and Malaysia due to the low competitiveness index, especially relating to the availability of information and communication technology, tourism service infrastructure, and health and hygiene issues. Other problems that also reduce competitiveness are institutional factors (especially in regions), security factors (prone to crime and dishonesty in transactions), and low awareness. Indonesia's desire to become a shopping paradise, as one part of the tourism industry, seems to be still difficult to realize due to the lack of support, for example the tax refund process that is still difficult for tourists, the small number of shops incorporated in tax returns, and the absence of factory outlets. Other problems that also hamper the development of tourism in Indonesia are the lack of promotional activities to attract tourists and the lack of focus on the development of tourist destinations which results in the nonoptimal achievement of the tourism sector. In addition, access to tourist destinations is often constrained by the price of domestic flight tickets which is more expensive than the price of 
international flight tickets. This makes tourists think twice about visiting other tourist destinations that must be reached by airplane, and finally the length of stay in Indonesia is not optimal.

The results of research by (Tayibnapis et al., 2020) state that naturally Indonesia has a large potential of natural and cultural resources to improve tourism, but the weakness lies in the quality of guides, tourism information, destination development, cleanliness, and inadequate tourism service infrastructure. The positive shift in ranking in 2017 and 2019 is due to the reduction in travel constraints and reduced travel costs, as well as the emergence of new tourist attractions and international events, such as sports tourism, fashion, music, and cultural shows. Indonesia's tourism sector actually has several advantages, one of which is the price is more competitive than in Singapore, Malaysia, and Thailand. But the main problem lies in the limited budget for promotion so competitive prices and attractive packages are not communicated to foreign tourists well. One of the examples is the "Pesona Indonesia" program. Actually there were many tourists who knew the program but they were not encouraged to come because there was no intensive promotion abroad so the achievement of tourism indicators was not optimal, in which the number of international visitors was only $12,948,000$ people with total revenues of approximately 12,530.8 million US dollars or an average revenue per visit of 967.8 US dollars in 2019 only.

Data from the Statistics Indonesia shows that the average length of stay of foreign and domestic guests at star classification hotels reached 1.8 days during July 2019 and increased compared to the average length of stay in July 2018 which was 1.73 days. While the occupancy rate of star hotel rooms in July 2019 averaged 56.73\% or down compared to the average in July 2018 which reached $59.30 \%$. At present and in the future the tourism sector is truly relied upon to reduce the current account deficit. The tourism sector was targeted to contribute 17.6 billion US dollars of foreign exchange with the arrival of 18 million foreign tourists in 2019. But the realization until September 1, 2019 only reached 9.31 million foreign tourists, even though Indonesia's tourism competitiveness improved two ranks to 40th out of 140 countries in 2019 with a score of 4.3 .

Indonesia's diversity, which includes more than 17 thousand islands, more than 300 ethnic groups, more than 700 languages, world heritage sites, and the third largest biodiversity, is a great potential for tourism development. In the framework of realizing Indonesia as a leading tourism destination, 6 programs have been launched: 
1. Developing leading destinations

2. Increasing competitiveness

3. Increasing tourism diversity

4. Increasing tourism integration

5. Strengthening as an Asian leading destination

6. Strengthening as a world leading destination.

It is time for tourism and creative industries to become the backbone of the national economy in order to overcome the current account deficit and the state budget deficit. The huge potential of tourism and the creative economy can have a big leap effect on the development of the nation's economy, especially since tourism actually grows from the bottom. Thus, collaboration between the Central and Regional Governments is needed so that the tourism sector is able to make a positive contribution to regional development, employment, retribution, foreign exchange, and others while always preserving the nature and local culture. Local wisdom should still be maintained and even introduced to travelers so that they will always maintain the sustainability of local tourist destinations, including implementing sustainable tourism. The development of tourism in Indonesia is not only in infrastructure, but also in ecosystems in an effort to support the success of tourist destinations, such as aspects of culture, creativity, and hospitality so that people around the tourist destinations are not just spectators. Thus the development of tourism is expected to provide economic benefits, maintain the environment, and empower people in the real sense. 